\title{
Desempenho de gotejadores autocompensantes com diferentes efluentes de esgoto doméstico
}

\author{
Lívia P. da Silva ${ }^{1}$, Manassés M. da Silva ${ }^{2}$, Marcus M. Correa ${ }^{2}$, \\ Fillipe C. D. Souza ${ }^{2} \&$ Ênio F. de F. e Silva ${ }^{2}$
}

\begin{abstract}
RESU M O
Objetivou-se, com esse trabalho, avaliar o desempenho hidráulico do gotejador Katif, da marca Plastro Brasil, tipo externo, autocompensante, utilizando-se efluentes oriundos de três diferentes formas de tratamento de esgoto doméstico. 0 experimento foi desenvolvido em condições de campo e laboratório. Os ensaios de campo consistiram na avaliação de um sistema de irrigação por gotejamento, sendo determinados, em três ocasiões, os testes de uniformidade. Em laboratório objetivou-se comparar 0 desempenho hidráulico dos emissores usados com um lote de emissores novos, em quatro faixas de pressão: 100, 150, 200 e $250 \mathrm{kPa}$. Foram obtidos os valores dos coeficientes de uniformidade de distribuição (CUD), de uniformidade estatística (CUE), e coeficiente de variação do fabricante (CVf). Os resultados obtidos permitiram concluir que a utilização de esgoto doméstico tratado por decanto digestor associado a um filtro digestor e a uma lagoa de estabilização, proporcionou os melhores resultados de uniformidade de distribuição e que, de modo geral, ocorreram perdas no desempenho hidráulico dos emissores com o uso contínuo de águas provenientes de estações de tratamento de esgoto doméstico.
\end{abstract}

Palavras-chave: reúso, entupimento, desempenho hidráulico

\section{Performance of auto compensating drippers with different effluents of domestic sewage}

\begin{abstract}
This study had the objective of evaluating the hydraulic performance of dripper Katif, brand Plastro Brazil, external type, auto compensating using effluent from three different treatments of domestic sewage. The experiment was conducted under field and laboratory conditions. The field test consisted in the evaluation of a drip irrigation system by uniformity tests which were conducted on three occasions. In the laboratory, the study aimed to compare the hydraulic performance of used emitters with a lot of new emitters in four pressure ranges: 100,150, 200 and $250 \mathrm{kPa}$. The values were obtained for the Christiansen U niformity Coefficient (CU C), D istribution U niformity Coefficients (CUD), and of Manufacturer Variation Coefficient (CVf). The results showed that the use of domestic sewage treated with decant digester associated with a filter digester and a stabilization pond provided the best results in distribution uniformity and, in general, the continuous use of wastewater provided losses in the hydraulic performance of emitters.
\end{abstract}

Key words: reuse, clogging, hydraulic performance

\footnotetext{
${ }^{1}$ Mestranda em Eng. de Sistemas Agrícolas, ESALQ/U SP. Av. Pádua Dias, 11, CEP 13418-900, Piracicaba, SP. Fone: (19) 3429-4123-230. E-mail: liviapreviatello@usp.br

2 U FRPE, Rua D. Manoel de Medeiros s/n, CEP 52171-900, Recife, PE. Fone: (81) 3320-6261. E-mail: manasses@dtr.ufrpe.br; metri@dtr.ufrpe.br; fillipecelestino@hotmail.com; enio.silva@dtr.ufrpe.br
} 


\section{INTRODUÇÃO}

O aumento da demanda por água, devido sobretudo ao crescimento populacional e às atividades produtivas decorrentes, somado à degradação ambiental dos corpos hídricos, tem criado um cenário de escassez hídrica em diversas regiões do globo. Este cenário de escassez vem influenciando mudanças de hábitos da população, em especial na atividade de agricultura irrigada, que vem buscando a redução no consumo de água e a otimização dos sistemas de irrigação.

No Brasil o uso de efluentes na agricultura ainda é incipiente e as alterações que podem ocorrer no solo e no sistema de irrigação são pouco conhecidas, necessitando de maiores investigações. Sabe-se que, apesar dos benefícios concretos ensejados com o aproveitamento de efluentes de esgoto doméstico na agricultura, a prática de reúso também provoca efeitos indesejáveis, em virtude principalmente da presença de alguns constituintes, como o sódio $\left(\mathrm{Na}^{+}\right)$e metais pesados.

Andrade et al. (2005), Rattan et al. (2005) e Varallo et al. (2010) avaliaram o impacto do reúso sobre as características físico-químicas de solos submetidos à irrigação com efluente de esgoto doméstico e constataram aumento na concentração de substâncias como o nitrato, ferro, zinco, cobre e manganês, além de maiores níveis de sódio e maior condutividade elétrica no solo; portanto, pode-se inferir que a utilização de efluentes deve ser acompanhada de algumas medidas de controle, com restrições de uso desse tipo de efluente em solos, principalmente naqueles sujeitos à presença de lençol freático raso.

Referente aos sistemas de irrigação e em virtude do quadro de escassez hídrica, observa-se preferência por sistemas de irrigação localizada que vem registrando notável expansão pela economia de água e energia, além de possibilitar a automação e a fertirrigação. De acordo com Cararo et al. (2006) e Najafi et al. (2010), no caso de aplicação de efluentes que possuem substâncias nocivas à saúde humana, os sistemas de irrigação por gotejamento também apresentam a vantagem de minimizar o contato direto da água contaminada com o agricultor e com o produto agrícola comercializado.

A irrigação por gotejamento se destaca, ainda, por sua facilidade de operação, por sua eficiência e uniformidade de distribuição de água, refletindo em melhor aproveitamento dos recursos hídricos e aumento na produção das culturas. De acordo com Souza et al. (2006), o coeficiente de uniformidade de distribuição da água e a eficiência de aplicação são os principais parâmetros utilizados na avaliação de sistema de irrigação por gotejamento, visto que expressam a qualidade da irrigação e são decisivos no planejamento e na operação desses sistemas.

Um sistema de irrigação bem projetado permite que se obtenha uniformidade de aplicação de água acima de 90\%, o que se considera um bom índice para a irrigação. Todavia, vários fatores podem afetar a uniformidade de distribuição da água nos sistemas de irrigação localizada, como pressão de serviço do emissor, velocidade da água na tubulação, alinhamento da linha lateral e entupimento dos emissores.

No entanto, os sistemas de irrigação por gotejamento são muito sensíveis à qualidade da água pela facilidade de ocorrer entupimentos em seus emissores. O entupimento de emissores resulta em variações na uniformidade de fluxo do emissor e na hidráulica da linha lateral, comprometendo a eficiência do sistema.

Resende et al. (2001) concluíram, no intuito de avaliar a uniformidade de distribuição de água em uma parcela de um sistema de irrigação por gotejamento após cinco anos de uso e a existência de processo de entupimento dos emissores utilizados, que a causa mais provável da baixa uniformidade de aplicação de água da parcela de irrigação avaliada foi resultado do entupimento de origem biológica. Batista et al. (2010) observaram, avaliando o efeito da aplicação de esgoto doméstico tratado sobre a uniformidade de aplicação de água de um sistema de irrigação por gotejamento, a formação de um biofilme, resultante da interação entre colônias de bactérias e algas, propiciando entupimentos parcial e total dos gotejadores, acarretando na diminuição da vazão e da uniformidade de aplicação.

Percebe-se, portanto, que o entupimento de emissores é fator limitante para a utilização de água residuária em sistemas de irrigação por gotejamento e que a magnitude do problema depende principalmente da qualidade de água utilizada, sendo fundamental a adoção de tipos de tratamentos mais eficientes, economicamente viáveis e ambientalmente seguros, para garantir que os sistemas de irrigação possam utilizar efluentes de melhor qualidade.

Neste sentido, o presente trabalho teve como objetivo avaliar o desempenho hidráulico de gotejadores autocompensantes sob efeito de três diferentes formas de tratamento de esgoto doméstico: reator UASB, associado a uma lagoa de polimento (UASB + LP); decanto digestor, associado a um filtro digestor e lagoa de estabilização (DG + FD + LE) e filtro digestor associado a uma lagoa de estabilização $(\mathrm{FD}+\mathrm{LE})$. Com a pesquisa, pretende-se testar a hipótese de que o tipo de tratamento do esgoto doméstico utilizado pode minimizar os riscos de entupimento em emissores de sistemas de irrigação por gotejamento.

\section{Material e MÉTOdos}

O experimento foi realizado no município de Ibimirim, PE, a $330 \mathrm{~km}$ de Recife. O efluente utilizado no teste de uniformidade em campo proveio de uma unidade piloto de tratamento de esgoto doméstico, constituída de uma estação elevatória, que conduz o esgoto doméstico bruto para os três sistemas de tratamento independentes: reator UASB associado a uma lagoa de polimento (UASB + LP), decanto digestor, associado a um filtro digestor e lagoa de estabilização (DG + FD + LE) e filtro digestor associado a uma lagoa de estabilização (FD + LE).

A unidade de reúso agrícola se constituiu de uma área cultivada com mamona da variedade BRS Energia (Ricinus communis L.) com $432 \mathrm{~m}^{2}$, em espaçamento de $1,0 \times 1,0 \mathrm{~m}$, na qual foram inseridos três sistemas de irrigação por gotejamento idênticos cujo layout de instalação (Figura 1) foi desenvolvido de modo a possibilitar a distribuição aleatória dos tratamentos estudados.

Utilizou-se uma linha lateral por fileira de plantas, com gotejadores espaçados $0,5 \mathrm{~m}$. Para cada tipo de efluente foi 


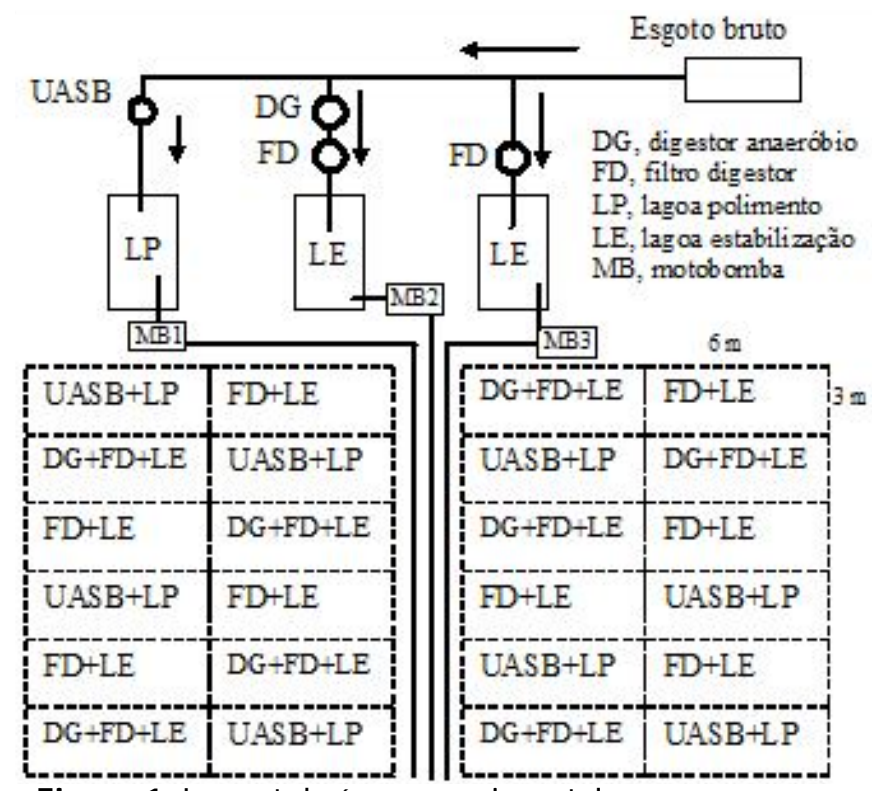

Figura 1. Layout da área experimental

instalado um filtro de disco com diâmetro de abertura de 120 Mesh, com o intuito de minimizar a entrada de sólidos suspensos grosseiros no sistema de irrigação; utilizou-se o gotejador Katif, da marca Plastro Brasil, do tipo externo, autocompensante, com vazão nominal de $3,75 \mathrm{~L} \mathrm{~h}^{-1}$ na faixa de pressão de serviço de 50 a $300 \mathrm{kPa}$, sendo o acionamento do sistema realizado manualmente.

As irrigações foram realizadas a cada dois dias em que o tempo médio de funcionamento do sistema de irrigação em campo, durante o ciclo da mamona foi de $48 \mathrm{~h}$ e o volume aplicado correspondente à evapotranspiração da cultura (ETc), calculada em tempo real, considerando-se a evapotranspiração de referência (ETo) e o coeficiente de cultivo $(\mathrm{kc})$ para cada fase de desenvolvimento fenológico da mamoneira, conforme a Tabela 1 (Allen et al., 1998).

Tabela 1. Coeficientes de cultivo $(\mathrm{kc}$ ) e fases fenológicas da mamoneira

\begin{tabular}{cccc}
\hline Fase & Descrição & $\begin{array}{c}\text { Duração } \\
\text { (dias) }^{(1)}\end{array}$ & $\mathbf{k}_{\mathbf{c}}{ }^{{ }^{(1)}}$ \\
I & Germinação, crescimento vegetativo & $0-25$ & 0,54 \\
II & Floração & $25-65$ & $0,54-1,15$ \\
III & Frutificação & $65-120$ & 1,15 \\
IV & Maturação e colheita & $65-120$ & $1,15-0,33$ \\
\hline
\end{tabular}

(1) Adaptado de Allen et al. (1998)

Obtiveram-se os dados meteorológicos através de Plataforma de Coleta de Dados (PCD) do Instituto Nacional de Meteorologia (INMET) localizada na Estação Experimental da UFRPE, distante aproximadamente três quilômetros das parcelas experimentais, obtidos diariamente pelo site do INMET. Para estimativa da ETo utilizou-se o modelo de PenmanMonteith-FAO (Allen et al., 1998).

Os testes de uniformidade foram conduzidos em três ocasiões: no início, aos 69 e 120 dias após a implantação do experimento. Vazões foram coletadas em quatro emissores ao longo da linha lateral, o primeiro gotejador, o segundo situado a $1 / 3$, o terceiro a $2 / 3$ do comprimento da linha e o último gotejador (Keller \& Karmeli, 1975). Oito linhas laterais foram avaliadas para cada tipo de sistema de tratamento de esgoto, perfazendo o total de 32 emissores por tratamento.

Com vista à avaliação da uniformidade de aplicação da água, determinaram-se: o coeficiente de uniformidade de distribuição - CUD (Eq. 1) e o coeficiente de uniformidade de estatístico CUE (Eq. 2). A vazão dos emissores foi medida de maneira direta, ou seja, o volume coletado no intervalo de $5 \mathrm{~min}$.

$$
\mathrm{CUD}=100\left(\frac{\mathrm{q}_{25}}{\mathrm{q}_{\mathrm{med}}}\right)
$$

em que:

CUD - coeficiente de uniformidade de distribuição, \%

$\mathrm{q}_{25}$ - vazão média do menor quartil, $\mathrm{L} \mathrm{h}^{-1}$

$\mathrm{q}_{\text {med }}$ - média aritmética das vazões coletadas, $\mathrm{L} \mathrm{h}^{-1}$

$$
\text { CUE }=100\left[1-\left(\frac{\mathrm{Sd}}{\mathrm{q}_{\mathrm{med}}}\right)\right]
$$

em que:

CUE - coeficiente de uniformidade estatístico, \%

Sd - desvio padrão

$\mathrm{q}_{\text {med }}$ - média aritmética das vazões coletadas, $\mathrm{L} \mathrm{h}^{-1}$

A água foi coletada com auxílio de 128 recipientes coletores posicionados abaixo dos gotejadores, apoiados sobre um suporte de madeira, o qual teve como objetivo permitir o manuseio de todos os copos de uma única vez, fazendo com que todos os emissores das linhas avaliadas fossem coletados juntamente, a fim de evitar possíveis erros na estabilização e aferição da pressão desejada. Os volumes foram mensurados com o auxílio de uma proveta de plástico graduada com precisão de $2 \mathrm{~mL}$.

Após a colheita da mamona e com a finalidade de avaliar os efeitos do esgoto doméstico sobre a durabilidade dos emissores, testes foram realizados em laboratório; para isto, o sistema de irrigação foi desmontado e transferido para o Laboratório de Hidráulica da Universidade Federal Rural de Pernambuco (UFRPE), onde foi montada uma bancada experimental constituída de um conjunto de três linhas laterais com sete metros de comprimento e 12 emissores por linha, espaçados $0,5 \mathrm{~m}$, uma bomba centrífuga de eixo horizontal de $0,5 \mathrm{cv}$, linha de sucção, linha de recalque e um manômetro tipo Bourdon glicerinado, com escala de 0 a $10 \mathrm{kPa}$.

Para avaliar o efeito do uso de diferentes efluentes sobre o desempenho hidráulico dos gotejadores coletaram-se as vazões dos 12 emissores de duas linhas laterais de cada tipo de tratamento perfazendo, no total, 72 emissores quando foram determinados, além do CUD e CUE, o Coeficiente de Variação de Fabricação - CVf (Eq. 3), para cada pressão analisada, tal como a curva vazão-pressão para cada tipo de tratamento.

$$
\mathrm{CVf}=\frac{\mathrm{Sd}}{\mathrm{q}_{\mathrm{med}}}
$$


em que:

CVf - coeficiente de variação do fabricante

Sd - desvio padrão

$\mathrm{q}_{\text {med }}$ - vazão média, $\mathrm{L} \mathrm{h}^{-1}$

Como critério de classificação dos coeficientes foram utilizados os valores especificados pela ASAE (1994), conforme a Tabela 2. Como testemunha se utilizaram, nos testes, três linhas laterais compostas de gotejadores novos, coletados aleatoriamente de um lote do fabricante. O sistema novo foi montado com as mesmas características do usado. Em todos os ensaios utilizou-se a água do campus da UFRPE.

Tabela 2. Classificação de coeficiente de uniformidade de distribuição (CUD), coeficiente de uniformidade estatístico (CU E) e coeficiente de variação do fabricante (CVf) segundo ASAE (1994)

\begin{tabular}{|c|c|c|c|c|}
\hline \multirow{2}{*}{ Classificação } & CUD & CUE & \multirow{2}{*}{ Classificação } & \multirow{2}{*}{$\begin{array}{l}\text { CVf } \\
(\%)\end{array}$} \\
\hline & \multicolumn{2}{|c|}{$(\%)$} & & \\
\hline Excelente & $100-94$ & $100-95$ & Excelente & $<5$ \\
\hline Bom & $87-81$ & $90-85$ & Média & $5-7$ \\
\hline Razoável & $75-68$ & $80-75$ & Marginal & $7-11$ \\
\hline Ruim & $62-56$ & $70-65$ & Ruim & $11-15$ \\
\hline Inaceitável & $<50$ & $<60$ & Inaceitável & $>15$ \\
\hline
\end{tabular}

\section{RESULTADOS E DISCUSSÃO}

Na Tabela 3 são apresentadas as características físicas e químicas do esgoto doméstico após a passagem pelos diferentes tipos de tratamentos de esgoto estudados.

Tabela 3. Caracterização física e química da água utilizada na irrigação. Valores médios de três avaliações, ao longo do experimento de campo

\begin{tabular}{lcrrr}
\hline \multirow{2}{*}{ Parâmetros* } & $\begin{array}{c}\text { Água } \\
\text { abastecimento }\end{array}$ & \multicolumn{3}{c}{ Efluentes* } \\
\cline { 3 - 5 } CE $\left(\mathrm{dS} \mathrm{m}^{-1}\right)$ & $\mathbf{U A S B}+$ LP & DG+ FD+ LE & FD+ LE \\
DBO $\left(\mathrm{mg} \mathrm{L}^{-1}\right)$ & 0,218 & 2,14 & 1,99 & 1,88 \\
DQO $\left(\mathrm{mg} \mathrm{L}^{-1}\right)$ & 0,9 & 36,10 & 47,30 & 65,00 \\
SST $\left(\mathrm{mg} \mathrm{L}^{-1}\right)$ & 10,8 & 395,50 & 384,60 & 694,90 \\
pH & 22,4 & 61,60 & 44,30 & 114,60 \\
& 6,53 & 6,87 & 6,88 & 6,95 \\
\hline
\end{tabular}

* LP, lagoa de polimento; $D G$, decanto digestor; FD, filtro digestor anaeróbio; $L E$, lagoa de estabilização; DQO, demanda química de oxigênio; DBO, demanda bioquímica de oxigênio; $C E$, condutividade elétrica; SST, sólidos suspensos totais, pH, potencial hidrogeniônico

Observa-se, dentre os parâmetros físico-químicos analisados, que os valores da condutividade elétrica (CE) e do $\mathrm{pH}$ foram semelhantes entre os tratamentos; já os valores de demanda química de oxigênio (DQO) e de sólidos suspensos totais (SST) nos efluentes tratados por FD+LE, foram superiores aos efluentes tratados por $\mathrm{UASB}+\mathrm{LP}$ e DG + FD + LE, podendo-se inferir que o tratamento filtro digesto, associado com lagoa de estabilização (FD + LE), produziu um efluente tratado com qualidade inferior para fins de irrigação localizada uma vez que, de acordo com os padrões de qualidade de água para irrigação, SST superior a $100 \mathrm{mg} \mathrm{L}^{-1}$ promove risco severo ao entupimento de emissores.

Capra \& Scicolone (2007) observaram, realizando testes de campo com águas residuárias de diferentes qualidades quanto ao teor de sólidos suspensos totais, que o teor de sólidos suspensos totais de $50 \mathrm{mg} \mathrm{L}^{-1}$ já causa problemas na uniformidade de emissão de água.

Os valores obtidos para os coeficientes de uniformidade de Christiansen e de Distribuição no início da implantação do experimento de campo foram de CUD $=94 \%$ e CUE $=94,5 \%$, respectivamente. Esses valores, de acordo com ASAE (1994), enquadram a uniformidade de aplicação de água na categoria excelente, demonstrando que o sistema de gotejamento foi bem dimensionado para as condições locais.

Os valores determinados para os coeficientes de uniformidade nas segunda e terceira avaliações ocorridas, respectivamente, aos 69 e 120 dias para os diferentes tratamentos, se encontram na Tabela 4.

Percebe-se redução na uniformidade de aplicação de água, em todos os tratamentos, permitindo inferir que o uso de esgoto doméstico tratado promoveu queda no desempenho hidráulico do emissor provocada pela presença de matéria orgânica no efluente.

A configuração de tratamento de esgoto mais eficiente foi o decanto digestor associado a um filtro digestor e lagoa de estabilização (DG + FD + LE), o que permitiu obter coeficientes de uniformidades superiores aos demais tratamentos estudados.

Analisando os coeficientes após 120 dias de submissão nos diferentes tratamentos, percebeu-se que a uniformidade no tratamento DG + FD + LE foi classificada boa, enquanto nos demais tratamentos foi classificada razoável ou ruim.

As menores uniformidades de distribuição foram observadas quando o esgoto doméstico foi tratado com filtro digestor associado a uma lagoa de estabilização (FD + LE) apresentando, na terceira avaliação CUD $=45,7 \%$ e CUE $=84,0 \%$. A menor remoção dos sólidos suspensos totais por este método deve ter sido a principal causa para as baixas uniformidades observadas.

Tabela 4. Classificação dos coeficientes obti dos na primeira etapa do experimento

\begin{tabular}{|c|c|c|c|c|c|c|c|}
\hline \multirow{2}{*}{ Avaliação } & \multirow{2}{*}{ Tratamento } & \multirow{2}{*}{$\begin{array}{l}\text { Vazão média } \\
\left(L h^{-1}\right)\end{array}$} & \multirow{2}{*}{$\begin{array}{l}\text { Valores } \\
\text { mínimos }\end{array}$} & \multirow{2}{*}{$\begin{array}{l}\text { Valores } \\
\text { máximos }\end{array}$} & \multirow{2}{*}{$\begin{array}{l}\text { Desvio } \\
\text { padrão }\end{array}$} & CUD & CUE \\
\hline & & & & & & \multicolumn{2}{|c|}{$(\%)$} \\
\hline $1 \underline{a}$ & Água abastecimento & 4,01 & 3,68 & 4,60 & 0,22 & 93,9 & 94,5 \\
\hline $2 \underline{a}$ & $\begin{array}{l}\text { UASB+ LP } \\
D G+F D+L E \\
F D+L E\end{array}$ & $\begin{array}{l}4,14 \\
4,14 \\
4,06 \\
\end{array}$ & $\begin{array}{l}3,32 \\
3,52 \\
3,72 \\
\end{array}$ & $\begin{array}{l}4,60 \\
4,76 \\
4,64 \\
\end{array}$ & $\begin{array}{l}0,45 \\
0,48 \\
0,79 \\
\end{array}$ & $\begin{array}{l}87,9 \\
84,0 \\
88,3 \\
\end{array}$ & $\begin{array}{l}89,2 \\
88,3 \\
88,6 \\
\end{array}$ \\
\hline $3 \underline{a}$ & $\begin{array}{l}\text { UASB+LP } \\
F D+D G+L E \\
F D+L E\end{array}$ & $\begin{array}{l}4,15 \\
4,07 \\
4,39\end{array}$ & $\begin{array}{l}3,48 \\
3,00 \\
3,24\end{array}$ & $\begin{array}{l}4,92 \\
4,52 \\
5,08\end{array}$ & $\begin{array}{l}0,41 \\
0,38 \\
0,44\end{array}$ & $\begin{array}{l}53,8 \\
70,0 \\
45,7\end{array}$ & $\begin{array}{l}84,8 \\
87,2 \\
84,0\end{array}$ \\
\hline
\end{tabular}


A associação de tratamentos pode ter sido a causa do melhor desempenho do sistema de tratamento DG+FD+LE. A passagem do esgoto por dois sistemas de tratamento conjugados, melhorou a qualidade físico-química da água, minimizando a formação de incrustações nas paredes dos dutos e emissores e, em contrapartida, mitigando a possibilidade de entupimento dos emissores.

Puig-Barguéz et al. (2005) observaram, avaliando a performance hidráulica de gotejadores utilizando dois tipos de efluentes tratados, lodo ativado e filtro de areia seguido de luz ultravioleta e cloração, a redução da uniformidade de aplicação de água no efluente tratado com lodo ativado e atribuíram a origem biológica como as principais causas do entupimento dos emissores. Os autores também observaram que o efluente que passou por tratamento terciário (luz ultravioleta) apresentou uniformidade de aplicação de água superior a 90\%, o que os levou a concluir que é importante seguir a desinfecção correta dos efluentes para utilização na irrigação por gotejamento.

Posteriormente, Puig-Barguéz et al. (2010) verificaram, ao estudar o efeito do entupimento pelo uso de água residuária tratada sobre o sistema de irrigação superficial e subsuperficial com dois tipos de emissores, autocompensantes e não compensantes, que a principal causa do entupimento foi a formação de biofilme.

$\mathrm{Na}$ Tabela 5 se encontram os valores dos coeficientes de uniformidade obtidos pelos emissores usados com cada tipo de efluente na faixa de pressão recomendada pelo fabricante.

Tabela 5. Classificação dos coeficientes do sistema de gotejamento usados

\begin{tabular}{|c|c|c|c|c|c|}
\hline \multirow{2}{*}{ Tratamento } & \multirow{2}{*}{$\begin{array}{l}\text { Pressão } \\
(\mathrm{kPa})\end{array}$} & \multirow{2}{*}{$\begin{array}{l}\text { Vazão } \\
\text { média } \\
\left(L h^{-1}\right)\end{array}$} & CUD & CUE & \multirow{2}{*}{$\begin{array}{l}\text { Desvio } \\
\text { padrão }\end{array}$} \\
\hline & & & \multicolumn{2}{|c|}{$(\%)$} & \\
\hline \multirow{4}{*}{$\begin{array}{c}\text { Água } \\
\text { abastecimento }\end{array}$} & 100 & 4,18 & 89,86 & 88,01 & 0,50 \\
\hline & 150 & 3,95 & 89,90 & 87,27 & 0,51 \\
\hline & 200 & 4,03 & 91,55 & 85,14 & 0,61 \\
\hline & 250 & 4,03 & 86,15 & 78,13 & 0,91 \\
\hline \multirow{4}{*}{ UASB + LP } & 100 & 4,33 & 73,50 & 84,85 & 0,64 \\
\hline & 150 & 4,14 & 80,58 & 84,82 & 0,63 \\
\hline & 200 & 4,06 & 78,59 & 84,30 & 0,64 \\
\hline & 250 & 3,96 & 70,11 & 77,87 & 0,88 \\
\hline \multirow{4}{*}{$D G+F D+L E$} & 100 & 4,34 & 91,82 & 93,58 & 0,28 \\
\hline & 150 & 4,14 & 88,64 & 91,08 & 0,37 \\
\hline & 200 & 4,15 & 85,71 & 86,83 & 0,55 \\
\hline & 250 & 4,00 & 77,10 & 81,00 & 0,76 \\
\hline \multirow{4}{*}{$F D+L E$} & 100 & 4,07 & 76,76 & 79,81 & 0,82 \\
\hline & 150 & 3,73 & 67,56 & 74,13 & 0,96 \\
\hline & 200 & 3,78 & 73,46 & 79,05 & 0,79 \\
\hline & 250 & 3,80 & 67,69 & 75,00 & 0,95 \\
\hline
\end{tabular}

Percebe-se, novamente, que o efluente tratado com decanto digestor associado a filtro digestor e lagoa de estabilização $(\mathrm{DG}+\mathrm{FD}+\mathrm{LE})$ promoveu maior uniformidade em todas as pressões estudadas. Comparando os emissores utilizados em campo com um lote de gotejadores novos, nota-se que os emissores novos apresentaram maiores valores de coeficientes de uniformidade classificando-se como excelente para as pressões de 100, 150 e $200 \mathrm{kPa}$, e como bom, para a de $250 \mathrm{kPa}$, indicando que para as menores pressões recomendadas pelo fabricante os emissores apresentaram a melhor uniformidade.
Evidencia-se, porém, a redução da uniformidade de aplicação da água com o uso contínuo de água residuária, permitindo maiores variações da vazão dentro da mesma faixa de pressão. Pletsch et al. (2009) observaram, avaliando a uniformidade de aplicação de água e o coeficiente de variação de vazão de tubos gotejadores, após o uso de esgoto doméstico tratado, redução da uniformidade de aplicação de água devido ao entupimento, e aumento do coeficiente de variação de vazão.

Resende et al. (2001) verificaram comprometimento das características hidráulicas de gotejadores autocompensantes com o uso contínuo de água enriquecida por nutrientes e o atribuíram ao entupimento parcial ou total dos emissores, provocado pelo crescimento de colônias de bactérias no interior dos dutos e nos gotejadores.

Analisando os valores obtidos para o coeficiente de variação de fabricação para os emissores novos e usados em cada tipo de efluente tratado (Tabela 6), não se verifica diferença significativa, a nível de 5\% de probabilidade, entre os emissores novos e os que utilizaram efluente proveniente de decanto digestor associado a um filtro digestor e lagoa de estabilização $(\mathrm{DG}+\mathrm{FD}+\mathrm{LE})$.

Entretanto, em todas as pressões analisadas o CVf ficou fora do padrão do recomendado pela ABNT (1986) e ASAE (1994), que classificam, como bons, os emissores que apresentam, no máximo, valores de CVf inferiores a $10 \%$.

Ao contrário do esperado, os emissores novos apresentaram valores de CVf superiores aos do tratamento DG + FD + LE; tal ocorrência pode ser atribuída ao fato dos emissores terem sido de lotes diferentes do fabricante, ocasionando altos valores de desvio padrão para os emissores novos, como indicado na Tabela 5. Segundo Talens (2009), variações de pressões influenciam na vazão dos emissores em razão da sua sensibilidade; sendo assim, outra causa que pode estar associada às variações das vazões dos emissores durante o ensaio, é a variação de pressão.

$O$ tratamento filtro digestor associado à lagoa de estabilização (FD + LE) foi o que proporcionou os piores resultados, apresentando CVf superiores a $20 \%$ em toda a faixa de pressão estudada (Tabela 6). Carvalho et al. (2006) e Koetz et al. (2006) também obtiveram coeficientes de variação de fabricação para esses emissores acima do recomendado pela ABNT. Dias et. al. (2005) consideraram a membrana elástica controladora de pressão, para esses tipos de emissores, muito sensível às intempéries.

No entanto, o tempo em que o emissor ficou exposto aos tratamentos não foi suficiente para a membrana elástica perder a função de reguladora de vazão. A Figura 2 apresenta a curva de vazão versus pressão para o gotejador Katif, 3,75 L h ${ }^{-1}$ e nela se percebe, apesar de ter sido possível verificar diferenças no comportamento hidráulico do emissor nos diferentes tratamentos estudados, que o tempo de exposição do emissor à água residuária tratada de esgoto doméstico não modificou sua característica autocompensante.

Pletsch et al. (2009) também obtiveram resultados semelhantes, ao observar alteração no comportamento hidráulico de gotejadores somente após 1000 h de aplicação de água residuária proveniente de esgoto doméstico tratado. Os resultados observados sugerem que pesquisas sejam conduzidas para o desenvolvimento de técnicas auxiliares ao tratamento de esgoto tradicional. 
Tabela 6. Parâmetros de desempenho dos gotejadores novos e usados

\begin{tabular}{|c|c|c|c|c|c|c|}
\hline \multirow{2}{*}{ Tratamento } & \multirow{2}{*}{$\begin{array}{c}\text { Pressão } \\
(\mathrm{kPa})\end{array}$} & \multirow{2}{*}{ CVf } & \multirow{2}{*}{ CVf médio } & \multirow{2}{*}{$\begin{array}{l}\text { Teste de } \\
\text { Duncan* }\end{array}$} & \multicolumn{2}{|c|}{ Classificação } \\
\hline & & & & & ABNT (1986) & ASAE (1994) \\
\hline \multicolumn{7}{|c|}{ Novos } \\
\hline & 100 & 11,99 & \multirow{4}{*}{15,36} & \multirow{4}{*}{$b$} & Médio & \multirow{4}{*}{$\begin{array}{l}\text { Ruim } \\
\text { Inaceitável } \\
\text { Médio } \\
\text { Inaceitável }\end{array}$} \\
\hline & 150 & 12,73 & & & Médio & \\
\hline & 200 & 14,86 & & & Bom & \\
\hline & 250 & 21,87 & & & Marginal & \\
\hline \multicolumn{7}{|c|}{ Usados } \\
\hline \multirow{4}{*}{ UASB + LP } & 100 & 15,15 & \multirow{4}{*}{17,04} & \multirow{4}{*}{$a b$} & Médio & \multirow{4}{*}{$\begin{array}{l}\text { Ruim } \\
\text { Inaceitável } \\
\text { Marginal } \\
\text { Inaceitável }\end{array}$} \\
\hline & 150 & 15,18 & & & Médio & \\
\hline & 200 & 15,70 & & & Bom & \\
\hline & 250 & 22,87 & & & Marginal & \\
\hline \multirow{4}{*}{$\mathrm{DG}+\mathrm{FD}+\mathrm{LE}$} & 100 & 6,42 & \multirow{4}{*}{11,88} & \multirow{4}{*}{$b$} & Médio & \multirow{4}{*}{$\begin{array}{l}\text { Ruim } \\
\text { Inaceitável } \\
\text { Ruim } \\
\text { Inaceitável }\end{array}$} \\
\hline & 150 & 8,92 & & & Médio & \\
\hline & 200 & 13,17 & & & Médio & \\
\hline & 250 & 19,00 & & & Marginal & \\
\hline \multirow{4}{*}{$\mathrm{FD}+\mathrm{LE}$} & 100 & 20,19 & \multirow{4}{*}{22,83} & \multirow{4}{*}{ a } & Marginal & Inaceitável \\
\hline & 150 & 25,87 & & & Marginal & Inaceitável \\
\hline & 200 & 20,95 & & & Médio & Inaceitável \\
\hline & 250 & 25,00 & & & Marginal & Inaceitável \\
\hline
\end{tabular}

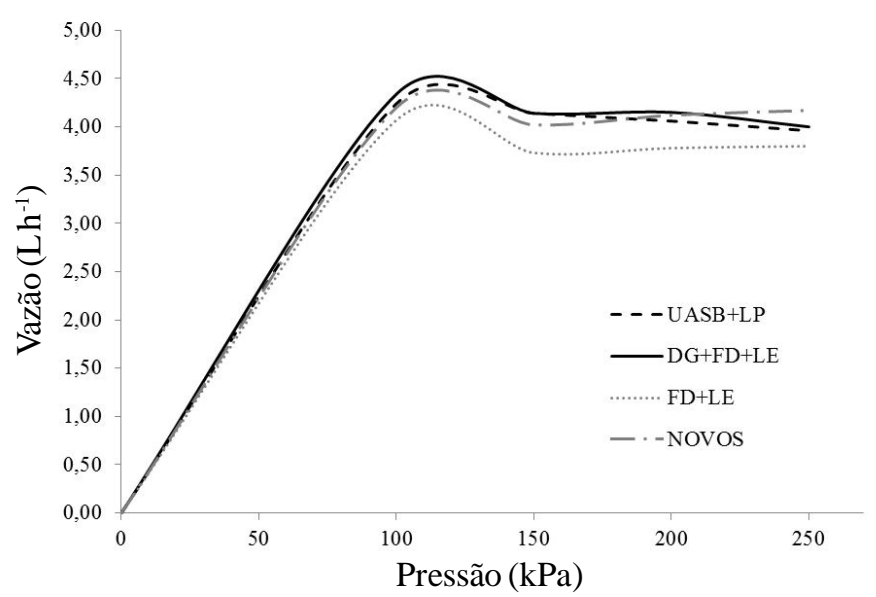

Figura 2. Comportamento hidráulico dos gotejadores novos e usados

\section{ConClusõES}

1. O sistema de tratamento decanto digestor, associado a um filtro digestor e lagoa de estabilização, promoveu melhor desempenho em sistemas de irrigação por gotejamento quando comparado com os demais tratamentos estudados.

2. As menores uniformidades de aplicação foram observadas quando se utilizou esgoto doméstico tratado por filtro digestor associado a uma lagoa de estabilização.

3. O uso de esgoto doméstico tratado promoveu queda no desempenho hidráulico do gotejador externo Katif, 3,75 $\mathrm{L} \mathrm{h}^{-1}$, na faixa de pressão de 50 a $200 \mathrm{kPa}$.

\section{Agradecimentos}

Os autores expressam seus agradecimentos à FINEP, pelo auxílio financeiro; ao $\mathrm{CNPq}$, pela concessão de bolsas de estudo e à UFRPE, pelo apoio logístico e de deslocamento à área experimental.

\section{LITERATURA CITADA}

ABNT - Associação Brasileira de Normas Técnicas. Requisitos mínimos para elaboração de projetos de irrigação localizada: PNBR 12:02-08-022. São Paulo: ABNT, 1986. 18p.

Allen, R. G.; Pereira, L. S.; Raes, D.; Smith, M. Crop evapotranspiration - Guidelines for computing crop water requirements. Rome: FAO. 1998. 297p. Irrigation and Drainage. Paper 56

Andrade, I. P.; Montenegro, A. A. A.; Silva, J. A. A; Freire, M. B. G. S.; Santos, T. E. M. Impacto do reúso de efluentes de esgoto no lixiviado de solos cultivados com milho. Revista Brasileira de Engenharia Agrícola e Ambiental, v.9, p.212216, 2005.

ASAE - American Society of Agricultural Engineers. Design and installation of microirrigation system. St. Joseph: ASAE, 1994.p.724-727.

Batista, R. O.; Souza, J. A. R.; Ferreira, D. C. Influência da aplicação de esgoto doméstico tratado no desempenho de um sistema de irrigação. Revista Ceres, v.57, p.18-22, 2010.

Capra, A.; Scicolone, B. Recycling of poor quality urban wastewater by drip irrigation systems. Journal of Cleaner Production, v.15, p.1529-1534, 2007.

Cararo, D. C.; Botrel, T. A.; Hills, D. J.; Leverenz, H. L. Analysis of clogging in drip emitters during wastewater irrigation. Applied Engineering in Agriculture, v.22, p.251257, 2006.

Carvalho, C. M.; Eloi, W. M.; Lima, S. C. R. V.; Pereira, J. M. G. Desempenho de um sistema de irrigação por gotejamento na cultura da goiaba. Irriga, v.11, p.36-46, 2006.

Dias, N. da S.; Medeiros, J. F. de; Teixeira, M. B. Avaliação de diferentes modelos, vazões e espaçamentos de gotejadores na irrigação do meloeiro. Irriga, v.10, p.263-271, 2005.

Keller, J.; Karmeli, D. Trickle irrigation design. California: Rain Bird Sprinkler Manufacturing Corporation, 1975. 133p. 
Koetz, M.; Coelho, G.; Costa, C. C.; Lima, E. P.; Souza, R. J. Efeitos da dose de potássio e da frequência de irrigação na produção da alface-americana em ambiente protegido. Engenharia Agrícola, v.26, p.730-737, 2006.

Najafi, P.; Tabatabaei, S. H.; Asgari, K. Evaluation of filtration and SDI application effects on treated wastewater quality index. African Journal of Agricultural Research, v.5, p.12501255, 2010.

Pletsch, T. A.; Cruz, R. L.; Mazzer, H. R.; Oliveira, E. F. Desempenho de gotejadores com uso de esgoto doméstico tratado. Irriga, v.14, p.243-253, 2009.

Puig-Barguéz, J.; Arbat, G; Barragán, J.; Cartagena, F. R. Hydraulic performance of drip subunits using WWTP effluents. Agricultural Water Management, v.77, p.249-262, 2005.

Puig-Barguéz, J.; Arbat, G.; Elbana, M.; Duran-Ros, M.; Barragán, J.; Cartagena, F. R.; Lamm, F. R. Effect of flushing frenquency on emitter clogging in microirrigation with effluents. Agricultural Water Management, v.97, p.883-891, 2010.
Rattan, R. K.; Datta, S. P.; Chhonkar, P. K.; Suribaru, K.; Singh, A. K. Long-term impact of irrigation with sewage effluents on heavy metal content in soils, crops and groundwater: A case study. Agriculture, Ecosystems \& Environment, v.109, p.310-322, 2005.

Resende, R. S.; Casarini, E.; Folegatti, M. V.; Coelho, R. D. Ocorrência de entupimento de origem biológica em sistema de irrigação por gotejamento. Revista Brasileira de Engenharia Agrícola e Ambiental, v.5, p.156-160, 2001.

Souza, L. O. C.; Mantovani, E. C.; Soares, A. A.; Ramos, M. M.; Freitas, P. S. L. Avaliação de sistemas de irrigação por gotejamento, utilizados na cafeicultura. Revista Brasileira de Engenharia Agrícola e Ambiental, v.10, p.541-548, 2006.

Talens, J. A. M. Riego localizado y fertirrigación. 4.ed. Madrid: Mundi-Prensa, 2009. 575p.

Varallo, A. C. T.; Carvalho, L.; Santoro, B. L.; Souza, C. F. Alterações nos atributos de um Latossolo Vermelho-amarelo irrigado com água de reúso. Revista Brasileira de Engenharia Agrícola e Ambiental, v.14, p.372-377, 2010. 